\title{
Effects of Different Rootstocks on Fruit Quality of Grafted Pepper (Capsicum annuum L.)
}

\author{
Yoonah Jang ${ }^{1,2}$, Ji-Hye Moon ${ }^{1}$, Ji-Weon Lee ${ }^{1}$, Sang Gyu Lee ${ }^{1}$, Seung Yu Kim ${ }^{1}$, and Changhoo Chun ${ }^{2,3 *}$ \\ ${ }^{1}$ National Institute of Horticultural \& Herbal Science, Rural Development Administration, Suwon 440-706, Korea \\ ${ }^{2}$ Department of Plant Science, Seoul National University, Seoul 151-921, Korea \\ ${ }^{3}$ Research Institute for Agriculture and Life Sciences, Seoul National University, Seoul 151-921, Korea
}

\begin{abstract}
This study was conducted to examine the effect of grafted peppers (Capsicum annuum) on different rootstocks on fruit quality. Three pepper cultivars, 'Nokkwang', 'Saengsaeng Matkkwari', and 'Shinhong' were grafted onto five commercial rootstocks that are known to be resistant to Phytophtora blight. Non-grafted or auto-grafted peppers were used as controls. Grafted plants were grown during two consecutive harvest periods by semi-forcing culture (April to August) and retarding culture (September to March the subsequent year). Full size green fruits were harvested and weighed weekly from June to August (Semi-forcing culture) and from December to March of the subsequent year (Retarding culture). The fruit size, weight, flesh thickness, and firmness were measured every month. Total marketable yield was not significantly influenced by either auto-graft of 'Nokkwang', 'Saengsaeng Matkkwari', and 'Shinhong' of pepper or grafted with the five commercial rootsctocks. By contrast, grafting influenced the apparent fruit quality of peppers. Fruit characteristics differed depending on the rootstock cultivars. However, the fruit characteristics of rootstock did not affect the fruit characteristics of scion grafted onto that rootstock. Fruit characteristics in each treatment differed among harvest time (first, second, and third harvest). Fruit quality parameters were also different as affected by the harvest period. In conclusion, apparent quality and textural property of pepper fruits were influenced by not only grafting with different rootstocksbut also by the harvest period and harvest time. Accordingly, rootstock/scion combination, the scion variety and the harvest period must be carefully chosen to get the desired optimal fruit quality.
\end{abstract}

Additional key words: apparent fruit quality, harvest period, harvest time, scion, textural property

\section{Introduction}

Grafting is the union of two or more pieces of living plant tissues that grow as a single plant (Lee and Oda, 2003). It is usually used to reduce infections by soil-borne pathogens and to enhance tolerance against abiotic stresses such as low and high temperatures, salt, flooding, etc. (Colla et al., 2010; Louws et al., 2010; Schwarz et al., 2010). Vegetable grafting is now common in Asia, parts of Europe, and the Middle East. In Korea, about $90 \%$ of Cucurbitaceous vegetables and $30 \%$ of Solanaceous vegetables are grafted onto various rootstocks (Lee et al., 2010).

Vegetable fruit quality for fresh consumption can be determined in terms of appearance (size, shape, color, absence of defects and decay), firmness, texture, flavor (sugars, acids, and aroma volatiles) and health-related compounds (desired compounds: minerals, vitamins, and carotenoids; undesired compounds: heavy metals, pesticides and nitrates) (Rouphael et al., 2010). It has been reported that the size, shape, color, texture, flavor, $\mathrm{pH}$, sugar, carotenoid content of fruits can be affected by grafting and the type of rootstock (Davis et al., 2008a, 2008b). Regarding the changes in fruit quality by grafting, there are several conflicting reports whether grafting effects are advantageous or disadvantageous (Davis et al., 2008a; Lee et al., 2010). More yield and larger fruits were reported in pepper (Gisbert et al., 2010) and watermelon (Miguel et al., 2004) when plants were grafted. Firmness and rind thickness, which are the typical attributes used to describe the fruit texture, were also reported to increase in watermelon (Yetisir et al., 2003) when grafted. In tomato,

\footnotetext{
*Corresponding author: changhoo@snu.ac.kr

※ Received 2 April 2013; Revised 9 July 2013; Accepted 13 August 2013. This study was supported by National Institute of Horticultural \& Herbal Science, Rural Development Administration, Republic of Korea (Project No. PJ00857101). 
soluble solid content and titratable acidity were improved by grafting (Flores et al., 2010). However, abnormal fruit qualities including reduced fruit soluble solid content, fruit fermentation, poor texture, and off-taste were also reported for grafted oriental melons and watermelons (Lee and Oda, 2003).

Pepper (Capsicum annumm) is the most important and widely cultivated vegetable in Korea. It is continuously produced in the same field or greenhouse. In order to prevent soil-borne diseases in continuous cropping, peppers are grafted onto the rootstocks that have resistance to Phytophthora blight. The rootstocks used for pepper grafting are the same species. The present ratio of grafting in peppers is $5-10 \%$ (Lee et al., 2010) and the use of grafted peppers is expected to increase. Grafted peppers are mostly cultivated in greenhouse for five to six months, and fruits are harvested continuously in green and unripe form. Some greenhouse pepper growers noted that the fruit length of grafted peppers is shorter or longer than non-grafted peppers, depending on rootstock genotypes. Tsaballa et al. (2013) also reported that grafting the round shaped pepper (scion) on the long shaped pepper (rootstock) changed the fruit shape of the scion, resulting in elongated fruits different from the normal round shape fruit in the scion. However, there is no information on how grafting affects the fruit quality of peppers. This study was conducted to examine the influence of grafting with different rootstocks on fruit quality of peppers and whether the fruit characteristics of grafted pepper were affected by rootstock cultivars.

\section{Materials and Methods}

\section{Plant Materials}

Three pepper cultivars, 'Nokkwang' (Seminis Inc.), 'Saengsaeng Matkkwari', and 'Shinhong' (Nongwoo Bio Co., Ltd.) were used as scions. Five commercial rootstocks resistant to Phytophthora blight, 'Kataguruma' (Sakada Korea Seed Co., Ltd.), 'Konesianhot' (Seminis Inc.), 'Koregon PR-380' (Koregon Seed Co., Ltd.), 'PR-power' (Nongwoo Bio Co., Ltd.), and 'Tantan' (Nongwoo Bio Co., Ltd.) were used as rootstocks. Non-grafted or auto-grafted (scion and rootstock were from the cultivars) scion seedlings served as controls.

\section{Growing Grafted Pepper Transplants}

Experiments were conducted during two consecutive harvest periods (semi-forcing culture and retarding culture). Peppers were cultivated from April to August in semi-forcing and from September to March the subsequent year in retarding culture.

Seeds of scion were sown seven days (Semi-forcing culture) and four days (Retarding culture) after sowing seeds of rootstocks in order to obtain seedlings of similar diameter with rootstocks. Seeds of scion and rootstock were sown into the 72-cell plug trays (W $280 \times$ L $540 \times$ H 45 mm, Bumnong Co., Ltd., Jeongeup, Korea) filled with commercial growing media (BM 2, Berger Group Ltd., Quebec, Canada). To promote germination, the plug trays were wrapped with vinyl chloride resin film and then placed in a germination chamber at $28^{\circ} \mathrm{C}$. After four days, the germinated seedlings were moved to a greenhouse. Seedlings were watered daily. A nutrient solution (electric conductivity $1.5 \mathrm{dS} \cdot \mathrm{m}^{-1}$ with 'Hanbang' for seedling, N-P-K-Ca-Mg = 8.0-2.4-2.4-4.8-1.6 $\mathrm{me} \cdot \mathrm{L}^{-1}$, Coseal Co., Ltd., Gunsan, Korea) was applied. Application frequency of the nutrient solution was determined depending on the plants growth stage (RDA, 2008b).

When the seedlings developed five or six true leaves at 36 days (semi-forcing culture) and 31 days (retarding culture) after sowing of scion seeds, scions were grafted onto rootstocks. The epicotyl of scion and rootstock were cut $1 \mathrm{~cm}$ below the first true leaf using a razor blade. After placing the scion on the rootstock, the grafted position was fixed with a grafting clip by slice grafting method. After grafting, plants were healed and acclimatized in the tunnel covered with double-layered plastic film and shade cloth in the greenhouse for one week (Lee et al., 2010). In order to prevent grafted plants from wilting by the excessive transpiration and to enhance healing, the tunnel was closed for the first three or four days of healing and acclimatization period. For the next three or four days, the opening and closing of the tunnel were done depending on the conditions of grafted plants and weather. This was done for the acclimatization of grafted plants to environmental conditions outside tunnel (RDA, 2008b). After the end of healing and acclimatization, grafted transplants were grown on the bench inside a glasshouse.

\section{Cultivation of Grafted Peppers in a Greenhouse}

Peppers were cultivated in a greenhouse covered with polyethylene film. After soil test, pre-plant broadcast N-P-Kmanure was applied to soil according to fertilizer recommendation for pepper (NAAS, 2006). Three rows were made and each row was mulched with black plastic film prior to planting. Two rows of drip irrigation tubing were placed under the plastic mulch in each row. The grafted and non-grafted transplants were transplanted at 38 days (April 6) and 31 days (September 27) after grafting, respectively. One row of pepper transplants were transplanted between drip irrigation tubing (35 $\mathrm{cm}$ between plants within row). The experiment was arranged in a randomized complete block design with three replicates.

Plants were pruned according to a 4-stem training system. 
Irrigation and additional fertilizer application was carried out using the standard procedures for pepper cultivation (RDA, 2008a). Additional fertilizer ('Hanbang' for green pepper cultivation, N-P-K-Ca-Mg $=10.8-8-3-7-4-2 \mathrm{me} \cdot \mathrm{L}^{-1}$, Gunsan, Korea) was applied depending on the growth conditions through a drip irrigation system. Air temperature and relative humidity data in the greenhouse were collected at an interval of 30 minute with a data logger (TR-72U, T\&D Co., Matsumoto, Japan). The greenhouses were heated by a warm air furnace system containing soil heating with electrothermal wire from April 6 to May 6 in semi-forcing culture, and from December 10 until the end of experiment in retarding culture, respectively. The minimum temperature of the greenhouse was set to $15^{\circ} \mathrm{C}$.

Full size green fruits were harvested weekly from June to August (Semi-forcing culture) and from December to March of the subsequent year (Retarding culture). All the fruits from each plant (fiveplants per each replicate) were harvested, counted and weighed. Fruits (ten fruits per each replicate) were selected and used for physical property test of fruit every month. Each fruit (five fruits per each replicate) was sliced into two (longitudinal) and the pericarp thickness at the center of the fruit was measured using a caliper gauge. Textural property of the fruit was measured by using a texture analyzer (EZ Test-100N, Shimadzu Co., Kyoto, Japan) equipped with a $5 \mathrm{~mm}$-diameter plunger. Compression force into the flesh at $7 \mathrm{~mm}$ depth was monitored at $2 \mathrm{~mm} \cdot \mathrm{s}^{-1}$ speed.

\section{Statistical Analysis}

The data were subjected to one-way, two-way, and three-way analyses of variance (ANOVA). Statistical computations were carried out using the Sigma Plot version 11 (Systat Software Inc., San Jose, CA, USA) and SAS version 9.1 (SAS Institute Inc., Cary, NC, USA) software.

\section{Results}

\section{Temperature and Relative Humidity during Cultivation}

The average daily maximum, mean, and minimum temperatures were $33.0,23.8$, and $17.6^{\circ} \mathrm{C}$ during semi-forcing culture, and $30.4,19.0$, and $13.0^{\circ} \mathrm{C}$ during retarding culture, respectively (Fig. 1). In semi-forcing culture, the daily mean and minimum temperature went up steadily. The daily mean temperature from late May and the daily minimum temperature from late June rose above $20^{\circ} \mathrm{C}$. In retarding culture, the temperatures hovered around average values. The average daily maximum, mean, and minimum relative humidity were $94.2,73.6$, and $41.0 \%$ during semi-forcing culture, and 83.7, 60.6, and $36.0 \%$ during retarding culture, respectively. In semi-forcing culture, relative humidity went up steadily. The daily maximum relative humidity reached $100 \%$ from late June until the end of experiment. In retarding culture, relative humidity fluctuated around average values.

\section{Yield of Grafted Peppers}

Total marketable yield was not significantly influenced by either auto-graft of 'Nokkwang', 'Saengsaeng Matkkwari', and 'Shinhong' of pepper or grafting with the five commercial rootsctocks (Fig. 2). Eventhough days to first harvests of the three cultivars in retarding culture were shorter than semiforcing culture, the total yields of 'Nokkwang' and 'Saengsaeng' in retarding culture was less than semi-forcing culture. The average marketable yields of 'Nokkwang' were 1,706 g per plant in semi-forcing culture, and 1,036 g in retarding culture. The average marketable yield of 'Saengsaeng Matkkwari' was $1,871 \mathrm{~g}$ per plant in semi-forcing culture, and $709 \mathrm{~g}$ in retarding culture. The average marketable yield of 'Shinhong' was $458 \mathrm{~g}$ per plant in semi-forcing culture, and $699 \mathrm{~g}$ in retarding culture.

\section{Apparent Fruit Quality of Grafted Peppers}

Even though the fruits of each scion cultivar had their own characteristic size and shape, these were influenced by grafting. Fruit characteristics of grafted peppers differed depending on the rootstock cultivars (Table 1). The scion cultivar $(\mathrm{S}) \times$ rootstock $(\mathrm{R})$ interaction was significant for fruit size and weight. The scion cultivar $(\mathrm{S}) \times$ harvest period $(\mathrm{H})$ interaction

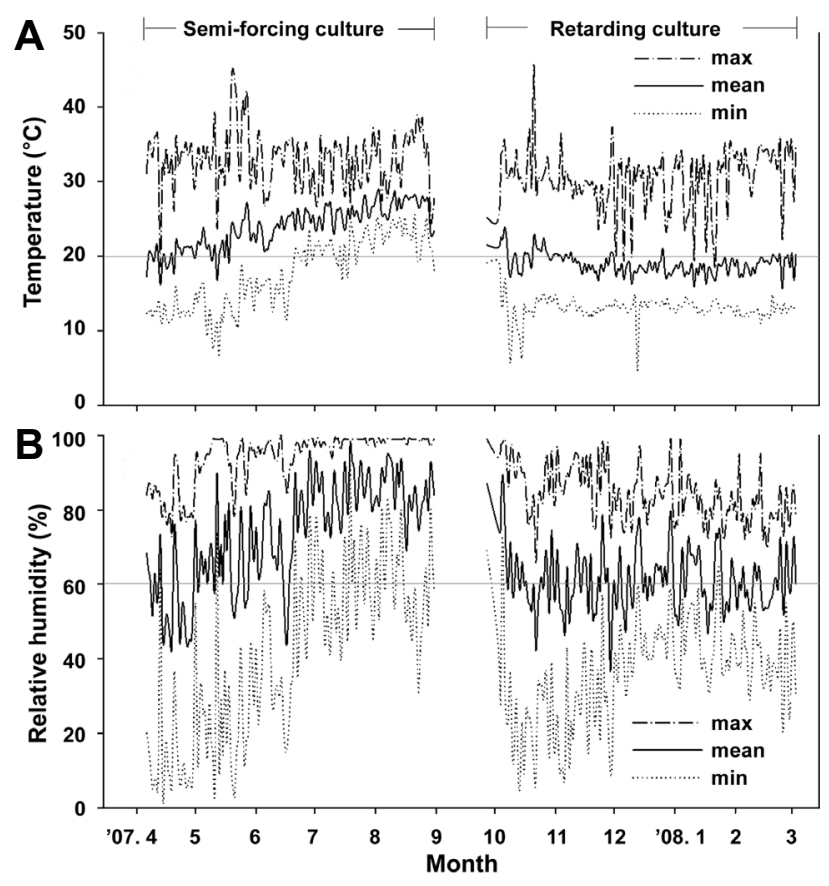

Fig. 1. Changes in daily maximum (max), mean, and minimum $(\mathrm{min})$ temperature $(\mathrm{A})$ and relative humidity $(\mathrm{B})$ during the cultivation of peppers. 


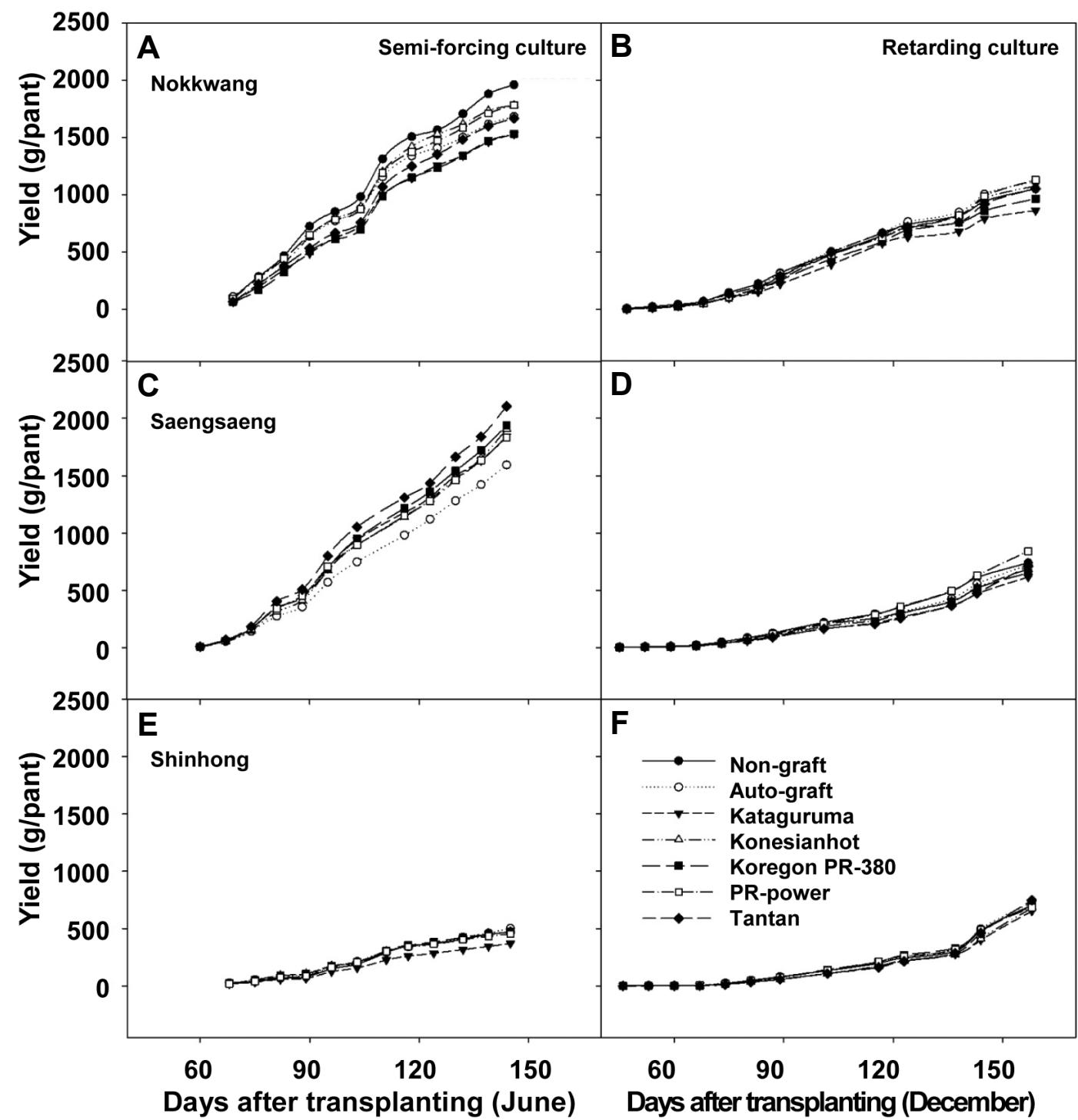

Fig. 2. Cumulative yield of marketable fruits of grafted peppers 'Nokkwang' (A and $B)$, 'Saengsaeng' (C and $D)$, and 'Shinhong' $(E$ and $F)$ as influenced by different rootstocks in semi-forcing and retarding culture.

was significant, but rootstock $(\mathrm{R}) \times$ harvest period $(\mathrm{H})$ interaction was not significant for the apparent quality and textural property of grafted pepper.

The average fruit length, fruit width, flesh thickness, fruit weight, and dry matter of 'Nokkwang' were 114.3, 15.0, and $1.99 \mathrm{~mm}, 10.58 \mathrm{~g}$, and $9.23 \%$, respectively (Table 1). In semi-forcing culture, fruit weight from the first and the second harvest differed depending on the rootstock cultivars, while fruit weight from the third harvest was not significantly influenced by grafting (Table 2). The fruit characteristics in each treatment also differed among harvest time (first, second, and third harvest). The fruit weight of pepper grafted onto 'Konesianhot' was the highest in the first harvest, but the fruit weight of non-grafted control plants was the highest in second harvest. The fruit length, flesh thickness, and fruit dry matter from the second harvest were significantly influenced by grafting, while those from the first or the third harvest were not. The length, shape index and weight of fruits decreased but the width and flesh thickness increased at the later stage of cultivation. In retarding culture, fruit length, weight, and dry matter were also affected by grafting, and ranged from 108.9 to $122.4 \mathrm{~mm}$, from 7.30 to $13.99 \mathrm{~g}$, and from 7.70 to $12.08 \%$, respectively, depending on rootstock genotypes and harvest time (Table 3). Fruit length and weight of pepper grafted onto 'Konesianhot' were found to be the highest. Fruit size, flesh thickness, fruit weight, and dry matter increased at the later stage of cultivation.

In 'Saengsaeng Matkkwari', the average fruit length, fruit width, flesh thickness, fruit weight, and dry matter of were $88.3,12.1$, and $1.28 \mathrm{~mm}, 4.25 \mathrm{~g}$, and $9.99 \%$, respectively (Table 1). In semi-forcing culture, the weight and hardness of fruit from the second harvest and fruit width and dry 
Table 1. ANOVA analysis of effects of scion cultivar,rootstock, and harvest period on the apparent quality and textural property of grafted pepper.

\begin{tabular}{|c|c|c|c|c|c|c|c|c|}
\hline & \multicolumn{6}{|c|}{ Fruit quality } & \multicolumn{2}{|c|}{ Textural property } \\
\hline & $\begin{array}{c}\text { Fruit } \\
\text { length } \\
(\mathrm{mm})\end{array}$ & $\begin{array}{l}\text { Fruit } \\
\text { width } \\
(\mathrm{mm})\end{array}$ & $\begin{array}{c}\text { Fruit } \\
\text { shape } \\
\text { index }\end{array}$ & $\begin{array}{c}\text { Flesh } \\
\text { thickness } \\
(\mathrm{mm})\end{array}$ & $\begin{array}{c}\text { Fruit } \\
\text { weight } \\
\text { (g) }\end{array}$ & $\begin{array}{c}\text { Dry } \\
\text { matter } \\
(\%)\end{array}$ & $\begin{array}{c}\text { Hardness } \\
\left(\mathrm{kN} \cdot \mathrm{m}^{-2}\right)\end{array}$ & $\begin{array}{l}\text { Strength } \\
\left(\mathrm{kN} \cdot \mathrm{m}^{-2}\right)\end{array}$ \\
\hline Scion cultivar (S) & $3,614.97^{* * *} y$ & $1,446.34^{* \star *}$ & $232.03^{* * t}$ & $664.84^{* * *}$ & $5,224.46^{\star \star *}$ & $234.68^{* * *}$ & $841.92^{* * *}$ & $722.91^{* * \star}$ \\
\hline Rootstock (R) & $7.2^{\star * \star}$ & $3.55^{* *}$ & $1.04^{\mathrm{ns}}$ & $0.90^{\mathrm{ns}}$ & $2.52^{*}$ & $2.66^{*}$ & $0.75^{\mathrm{ns}}$ & $0.70^{\mathrm{ns}}$ \\
\hline Harvest period $(\mathrm{H})$ & $855.91^{* \star *}$ & $322.09^{* \star \star}$ & $74.07^{* \star *}$ & $8.67^{* *}$ & $119.71^{\star \star \star}$ & $67.89^{* * \star}$ & $102.15^{\star \star \star}$ & $255.50^{* * *}$ \\
\hline Block & $29.60^{* * *}$ & $6.06^{* *}$ & $4.68^{* \star}$ & $1.66^{\mathrm{ns}}$ & $32.23^{* * *}$ & $52.12^{* \star *}$ & $1.09^{\mathrm{ns}}$ & $11.80^{* \star \star}$ \\
\hline$S \times R$ & $2.64^{* *}$ & $1.95^{*}$ & $1.42^{\mathrm{ns}}$ & $1.27^{\mathrm{ns}}$ & $2.73^{* *}$ & $1.47^{\mathrm{ns}}$ & $1.07^{\mathrm{ns}}$ & $2.37^{\star *}$ \\
\hline $\mathrm{S} \times \mathrm{H}$ & $186.07^{\star \star \star}$ & $20.78^{\star \star \star}$ & $75.00^{* \star \star}$ & $36.73^{\star \star \star}$ & $55.26^{\star \star \star}$ & $101.34^{\star \star \star}$ & $318.96^{\star \star \star}$ & $333.08^{* \star \star}$ \\
\hline $\mathrm{R} \times \mathrm{H}$ & $1.66^{\mathrm{ns}}$ & $1.22^{\mathrm{ns}}$ & $1.67^{\mathrm{ns}}$ & $0.94^{\mathrm{ns}}$ & $2.09^{\mathrm{ns}}$ & $3.17^{\star \star}$ & $1.39^{\mathrm{ns}}$ & $0.89^{\text {ns }}$ \\
\hline $\mathrm{S} \times \mathrm{R} \times \mathrm{H}$ & $1.56^{\mathrm{ns}}$ & $1.27^{\mathrm{ns}}$ & $1.44^{\mathrm{ns}}$ & $1.20^{\mathrm{ns}}$ & $1.29^{\mathrm{ns}}$ & $1.96^{*}$ & $0.94^{\mathrm{ns}}$ & $0.44^{\mathrm{ns}}$ \\
\hline \multicolumn{9}{|l|}{ Scion cultivar } \\
\hline Nokkwang & $114.3 a^{x}$ & $15.0 \mathrm{a}$ & $7.7 \mathrm{a}$ & $1.99 a$ & $10.58 \mathrm{a}$ & $9.23 \mathrm{c}$ & $675 a$ & 7,507 a \\
\hline Saengsaeng & $88.3 \mathrm{~b}$ & $12.1 \mathrm{c}$ & $7.3 \mathrm{~b}$ & $1.28 \mathrm{c}$ & $4.25 \mathrm{c}$ & $9.99 \mathrm{~b}$ & $416 \mathrm{c}$ & $3,847 \mathrm{c}$ \\
\hline Shinhong & $84.2 \mathrm{c}$ & $12.4 \mathrm{~b}$ & $6.9 \mathrm{c}$ & $1.73 b$ & $5.50 \mathrm{~b}$ & $10.68 \mathrm{a}$ & $487 \mathrm{~b}$ & $5,393 \mathrm{~b}$ \\
\hline \multicolumn{9}{|l|}{ Rootstock } \\
\hline Non-graft & $97.4 \mathrm{a}$ & $13.3 \mathrm{a}$ & $7.3 \mathrm{a}$ & $1.75 \mathrm{a}$ & $7.50 \mathrm{a}$ & $9.95 a b$ & 556 a & 5,847 a \\
\hline Auto-graft & $95.8 \mathrm{~b}$ & $13.2 \mathrm{a}$ & $7.3 \mathrm{a}$ & $1.67 \mathrm{a}$ & $6.79 \mathrm{bc}$ & $9.84 a b$ & $524 a$ & 5,487 a \\
\hline Kataguruma & $95.4 \mathrm{~b}$ & $13.1 \mathrm{a}$ & $7.3 \mathrm{a}$ & $1.67 \mathrm{a}$ & $6.73 \mathrm{c}$ & $10.07 \mathrm{a}$ & $535 a$ & 5,540 a \\
\hline Konesianhot & $96.4 a b$ & $13.3 \mathrm{a}$ & $7.3 \mathrm{a}$ & $1.68 \mathrm{a}$ & $6.96 \mathrm{~b}$ & $10.06 \mathrm{a}$ & 520 a & 5,350 a \\
\hline Koregon PR-380 & $95.7 \mathrm{~b}$ & $13.2 \mathrm{a}$ & $7.3 \mathrm{a}$ & $1.62 \mathrm{a}$ & $6.76 \mathrm{bc}$ & $10.01 \mathrm{ab}$ & 526 a & 5,437 a \\
\hline PR-power & $95.7 \mathrm{~b}$ & $13.3 \mathrm{a}$ & $7.3 \mathrm{a}$ & $1.67 \mathrm{a}$ & $6.84 \mathrm{bc}$ & $9.81 \mathrm{~b}$ & 532 a & 5,406 a \\
\hline Tantan & $96.5 \mathrm{ab}$ & $13.2 \mathrm{a}$ & $7.4 \mathrm{a}$ & $1.68 \mathrm{a}$ & $6.78 \mathrm{bc}$ & $9.89 a b$ & $521 \mathrm{a}$ & 5,338 a \\
\hline \multicolumn{9}{|l|}{ Cultivar type } \\
\hline Semi-forcing culture & 101.6 a & $13.7 \mathrm{a}$ & $7.5 \mathrm{a}$ & $1.71 \mathrm{a}$ & $7.30 \mathrm{a}$ & $10.18 \mathrm{a}$ & $506 \mathrm{~b}$ & $4,947 \mathrm{~b}$ \\
\hline Retarding culture & $91.1 \mathrm{~b}$ & $12.7 \mathrm{~b}$ & $7.2 \mathrm{a}$ & $1.64 \mathrm{~b}$ & $6.49 \mathrm{~b}$ & $9.66 \mathrm{~b}$ & $550 \mathrm{a}$ & 5,943 a \\
\hline
\end{tabular}

${ }^{\mathrm{z}}$ Fruit shape index $=$ fruit width/fruit length.

${ }^{y}$ Data were analyzed by three-way variance (ANOVA). ${ }^{* * *, * * *}$ indicates F-test significance at the $P \leq 0.05, P \leq 0.01$, and $P \leq$ 0.001 level, respectively.

${ }^{\mathrm{x}}$ Means separation within each column by Duncan's multiple range test $(P \leq 0.05)$.

matter from the third harvest differed depending on the rootstock cultivars, while fruit characteristics from the first harvest were not significantly influenced by grafting (Table 4). Fruit width, fruit shape index, flesh thickness, and weight were affected by harvest time. Fruit width decreased but fruit shape index and weight increased at the later stage of cultivation. Fruit size and weight in retarding culture were smaller than those in the semi-forcing culture. In retarding culture, the width, shape index, and weight of fruit from the first harvest and the fruit width, flesh thickness, and dry matter from the second harvest differed depending on the rootstock cultivars, while fruit characteristics from the third harvest were not significantly influenced by grafting (Table 5). Fruit width, flesh thickness, and fruit weight increased at the later stage of cultivation.

In 'Shinhong', the average fruit length, fruit width, flesh thickness, fruit weight, and dry matter of were 84.2, 12.4, and $1.73 \mathrm{~mm}, 5.50 \mathrm{~g}$, and $10.68 \%$, respectively (Table 1). Fruit size, weight and flesh thickness in retarding culture were smaller than those in semi-forcing culture. In semi-forcing culture, the fruit size, flesh thickness and dry matter from first harvest were affected by grafting, while fruit characteristics from the third harvest were not significantly influenced by grafting (Table 6). The length and weight of fruit grafted onto 'Koregon PR-380' were greatest in the first harvest. Fruit length and weight decreased at later stage of cultivation. In retarding culture, the length and weight of fruit from the second harvest and the fruit length from the third harvest differed depending on the rootstock cultivars, while fruit characteristics from the first harvest were not significantly influenced by grafting (Table 7). The fruit length and weight of pepper grafted onto 'Koregon PR-380' were highest in the 
Table 2. Effects of different rootstocks on the apparent quality and textural property of 'Nokkwang' pepper fruits at different harvest time in the semi-forcing culture.

\begin{tabular}{|c|c|c|c|c|c|c|c|c|}
\hline \multirow[b]{2}{*}{ Rootstock } & \multicolumn{6}{|c|}{ Fruit quality } & \multicolumn{2}{|c|}{ Textural property } \\
\hline & $\begin{array}{l}\text { Fruit } \\
\text { length } \\
(\mathrm{mm})\end{array}$ & $\begin{array}{l}\text { Fruit } \\
\text { width } \\
(\mathrm{mm})\end{array}$ & $\begin{array}{l}\text { Fruit } \\
\text { shape } \\
\text { index }\end{array}$ & $\begin{array}{l}\text { Flesh } \\
\text { thickness } \\
(\mathrm{mm})\end{array}$ & $\begin{array}{c}\text { Fruit } \\
\text { weight } \\
\text { (g) }\end{array}$ & $\begin{array}{c}\text { Dry } \\
\text { matter } \\
(\%)\end{array}$ & $\begin{array}{l}\text { Hardness } \\
\left(\mathrm{kN} \cdot \mathrm{m}^{-2}\right)\end{array}$ & $\begin{array}{l}\text { Strength } \\
\left(\mathrm{kN} \cdot \mathrm{m}^{-2}\right)\end{array}$ \\
\hline \multicolumn{9}{|l|}{ First harvest ${ }^{y}$} \\
\hline Non-graft & $123.4 a^{x}$ & $14.6 \mathrm{a}$ & $8.6 \mathrm{a}$ & $1.58 \mathrm{a}$ & $10.86 \mathrm{c}$ & $8.90 \mathrm{a}$ & 569 a & $5,551 \mathrm{a}$ \\
\hline Auto-graft & 123.9 a & $14.9 \mathrm{a}$ & $8.4 \mathrm{a}$ & $1.54 \mathrm{a}$ & 11.29 bc & $8.70 \mathrm{a}$ & $537 a$ & 5,363 a \\
\hline Kataguruma & $123.8 \mathrm{a}$ & $14.5 \mathrm{a}$ & $8.6 \mathrm{a}$ & $1.57 \mathrm{a}$ & $11.68 \mathrm{ab}$ & $8.67 \mathrm{a}$ & 545 a & 5,446 a \\
\hline Konesianhot & $127.4 \mathrm{a}$ & $14.7 \mathrm{a}$ & $8.7 \mathrm{a}$ & $1.66 \mathrm{a}$ & $12.13 \mathrm{a}$ & $8.49 a$ & 568 a & 5,331 a \\
\hline Koregon PR-380 & $124.8 \mathrm{a}$ & $14.4 \mathrm{a}$ & $8.7 \mathrm{a}$ & $1.50 \mathrm{a}$ & $11.31 \mathrm{bc}$ & 8.92 a & 569 a & 5,275 a \\
\hline PR-power & $124.3 \mathrm{a}$ & $14.6 \mathrm{a}$ & $8.5 \mathrm{a}$ & $1.59 \mathrm{a}$ & $11.09 \mathrm{bc}$ & $8.90 \mathrm{a}$ & 550 a & $5,577 a$ \\
\hline Tantan & $123.2 \mathrm{a}$ & $14.8 \mathrm{a}$ & $8.4 \mathrm{a}$ & $1.62 \mathrm{a}$ & $11.54 \mathrm{a}-\mathrm{c}$ & $8.75 \mathrm{a}$ & 547 a & 5,135 a \\
\hline \multicolumn{9}{|l|}{ Second harvest } \\
\hline Non-graft & $122.2 \mathrm{a}$ & $16.0 \mathrm{a}$ & $7.8 \mathrm{a}$ & $2.12 \mathrm{a}$ & $11.73 \mathrm{a}$ & $9.11 \mathrm{~b}$ & $558 a b$ & 5,122 a-c \\
\hline Auto-graft & $123.0 \mathrm{a}$ & $15.5 \mathrm{a}$ & 7.9 a & $1.85 \mathrm{bc}$ & $11.53 \mathrm{a}$ & $9.45 a b$ & $520 \mathrm{~b}$ & $5,082 a-c$ \\
\hline Kataguruma & $119.4 a b$ & $15.3 \mathrm{a}$ & $7.9 \mathrm{a}$ & $2.03 a b$ & $11.26 \mathrm{a}$ & $9.11 \mathrm{~b}$ & 609 a & 5,666 a \\
\hline Konesianhot & $119.9 \mathrm{ab}$ & 15.6 a & $7.7 \mathrm{a}$ & $1.78 \mathrm{~cd}$ & $11.03 \mathrm{a}$ & $9.65 a b$ & $616 a$ & $5,457 a b$ \\
\hline Koregon PR-380 & $115.7 b$ & $15.4 \mathrm{a}$ & $7.6 \mathrm{a}$ & $1.62 \mathrm{~d}$ & $10.68 a b$ & $8.96 \mathrm{~b}$ & $525 \mathrm{~b}$ & $5,337 a b$ \\
\hline PR-power & $115.8 \mathrm{~b}$ & $15.8 \mathrm{a}$ & $7.4 \mathrm{a}$ & $1.83 \mathrm{bc}$ & $11.15 \mathrm{a}$ & $9.08 \mathrm{~b}$ & $546 a b$ & 4,892 bc \\
\hline Tantan & $118.5 a b$ & $15.4 \mathrm{a}$ & $7.7 \mathrm{a}$ & $1.97 \mathrm{a}-\mathrm{c}$ & $10.01 \mathrm{~b}$ & $9.87 \mathrm{a}$ & $511 \mathrm{~b}$ & $4,562 \mathrm{c}$ \\
\hline \multicolumn{9}{|l|}{ Third harvest } \\
\hline Non-graft & $102.3 \mathrm{a}$ & $16.3 \mathrm{a}$ & $6.3 \mathrm{~b}$ & $2.42 \mathrm{a}$ & $9.76 \mathrm{a}$ & $9.80 \mathrm{a}$ & 581 a & 5,676 a \\
\hline Auto-graft & 100.7 a & $15.7 \mathrm{a}$ & $6.5 \mathrm{ab}$ & $2.33 a$ & $8.86 a$ & 9.69 a & 546 a & 5,451 a \\
\hline Kataguruma & $103.3 \mathrm{a}$ & $15.3 \mathrm{a}$ & $6.8 \mathrm{a}$ & $2.29 a$ & 8.75 a & $10.26 a$ & 568 a & 5,647 a \\
\hline Konesianhot & $99.5 \mathrm{a}$ & $15.8 \mathrm{a}$ & $6.3 \mathrm{~b}$ & $2.27 \mathrm{a}$ & $8.83 a$ & $9.95 \mathrm{a}$ & 555 a & 5,186 a \\
\hline Koregon PR-380 & $100.5 \mathrm{a}$ & 15.8 a & $6.4 \mathrm{~b}$ & $2.17 a$ & 9.02 a & $9.61 \mathrm{a}$ & 565 a & 5,768 a \\
\hline PR-power & $102.3 \mathrm{a}$ & $16.4 \mathrm{a}$ & $6.3 \mathrm{~b}$ & $2.23 \mathrm{a}$ & $9.12 \mathrm{a}$ & $9.38 \mathrm{a}$ & $550 \mathrm{a}$ & 5,133 a \\
\hline Tantan & $105.3 \mathrm{a}$ & $15.7 a$ & $6.8 \mathrm{ab}$ & $2.30 a$ & $8.80 a$ & $9.27 a$ & $551 a$ & $5,320 a$ \\
\hline \multicolumn{9}{|l|}{$P$ value } \\
\hline Rootstock (A) & 0.2479 & 0.0155 & 0.0689 & $<0.0001$ & 0.0603 & 0.6247 & 0.0344 & 0.0866 \\
\hline Harvest time (B) & 0.0002 & 0.0082 & $<0.0001$ & 0.0002 & 0.0049 & 0.1987 & 0.9828 & 0.5503 \\
\hline$A \times B$ & 0.0004 & 0.4687 & 0.0508 & 0.0566 & 0.0001 & $<0.0001$ & 0.2072 & 0.4894 \\
\hline
\end{tabular}

${ }^{\mathrm{z}}$ Fruit shape index $=$ fruit width/fruit length.

${ }^{y}$ In semi-forcing culture, first, second, and third harvest were done on June 21, July 19, and August 23, respectively.

'Mean separation within columns for each harvest time by Duncan's multiple range test $(P \leq 0.05)$.

second harvest, but the fruit length of pepper grafted onto 'PR-power' was the highest in the third harvest. Fruit size, flesh thickness, fruit weight, and dry matter increased at the later stage of cultivation.

\section{Textural Property of Grafted Peppers}

The average hardness and strength of 'Nokkwang', 'Saengsaeng Matkkwari', and 'Shinhong' were 675, 7,507, 416, 3,847, 487 , and $5,353 \mathrm{kN} \cdot \mathrm{m}^{-2}$, respectively (Table 1 ). The hardness and strength of 'Nokkwang' in retarding culture were greater than those in semi-forcing culture (Tables 2 and 3). However, the hardness and strength of 'Saengsaeng Matkkwari' in semi-forcing culture were greater than those in retarding culture (Tables 4 and 5). In semi-forcing culture of 'Nokkwang', the fruit hardness from second harvest was affected by grafting, and the greatest in peppers grafted onto 'Konesianhot'. The hardness and strength of 'Saengsaeng Matkkwari' increased at the later stage of cultivation. In retarding culture, the hardness of 'Nokkwang' and the hardness and strength of 'Shinhong' also increased at the later stage of cultivation (Tables 6 and 7). 
Table 3. Effects of differentrootstocks on the apparent quality and textural property of 'Nokkwang' pepper fruits at different harvest time in retarding culture.

\begin{tabular}{|c|c|c|c|c|c|c|c|c|}
\hline \multirow[b]{2}{*}{ Rootstock } & \multicolumn{6}{|c|}{ Fruit quality } & \multicolumn{2}{|c|}{ Textural property } \\
\hline & $\begin{array}{l}\text { Fruit } \\
\text { length } \\
(\mathrm{mm})\end{array}$ & $\begin{array}{l}\text { Fruit } \\
\text { width } \\
(\mathrm{mm})\end{array}$ & $\begin{array}{c}\text { Fruit } \\
\text { shape } \\
\text { index }\end{array}$ & $\begin{array}{c}\text { Flesh } \\
\text { thickness } \\
(\mathrm{mm})\end{array}$ & $\begin{array}{c}\text { Fruit } \\
\text { weight } \\
\text { (g) }\end{array}$ & $\begin{array}{c}\text { Dry } \\
\text { matter } \\
(\%)\end{array}$ & $\begin{array}{c}\text { Hardness } \\
\left(\mathrm{kN} \cdot \mathrm{m}^{-2}\right)\end{array}$ & $\begin{array}{l}\text { Strength } \\
\left(\mathrm{kN} \cdot \mathrm{m}^{-2}\right)\end{array}$ \\
\hline \multicolumn{9}{|l|}{ First harvest $^{y}$} \\
\hline Non-graft & $108.9 b^{x}$ & $13.4 \mathrm{a}$ & $8.2 \mathrm{a}$ & $1.80 \mathrm{a}$ & $7.95 \mathrm{ab}$ & $8.07 \mathrm{a}$ & 694 a & $8,912 a$ \\
\hline Auto-graft & $109.6 \mathrm{~b}$ & $13.2 \mathrm{a}$ & $8.3 \mathrm{a}$ & $1.79 \mathrm{a}$ & $7.77 \mathrm{~b}$ & $7.88 \mathrm{a}$ & $673 a$ & $8,210 a$ \\
\hline Kataguruma & $109.2 b$ & $12.9 \mathrm{a}$ & $8.5 \mathrm{a}$ & $1.75 \mathrm{a}$ & $7.93 \mathrm{ab}$ & $7.97 \mathrm{a}$ & $650 \mathrm{a}$ & $8,171 \mathrm{a}$ \\
\hline Konesianhot & $116.9 \mathrm{a}$ & $13.4 \mathrm{a}$ & $8.8 \mathrm{a}$ & $1.72 \mathrm{a}$ & $8.76 \mathrm{a}$ & $7.70 \mathrm{a}$ & $640 \mathrm{a}$ & $7,219 a$ \\
\hline Koregon PR-380 & $110.8 \mathrm{~b}$ & $13.3 \mathrm{a}$ & $8.4 \mathrm{a}$ & $1.80 \mathrm{a}$ & $7.67 \mathrm{~b}$ & $8.01 \mathrm{a}$ & 655 a & $7,885 \mathrm{a}$ \\
\hline PR-power & $110.2 b$ & $12.7 \mathrm{a}$ & $8.7 \mathrm{a}$ & $1.65 \mathrm{a}$ & $7.53 \mathrm{~b}$ & $8.06 \mathrm{a}$ & 646 a & $7,560 \mathrm{a}$ \\
\hline Tantan & $107.6 \mathrm{~b}$ & $12.9 \mathrm{a}$ & $8.4 \mathrm{a}$ & $1.90 \mathrm{a}$ & $7.30 \mathrm{~b}$ & $8.30 \mathrm{a}$ & 695 a & $8,984 a$ \\
\hline \multicolumn{9}{|l|}{ Second harvest } \\
\hline Non-graft & $112.0 \mathrm{bc}$ & $15.4 \mathrm{a}$ & $7.3 \mathrm{a}$ & $2.18 \mathrm{a}$ & $11.62 \mathrm{a}$ & $8.84 a$ & 779 a & 9,502 a \\
\hline Auto-graft & 109.9 bc & $15.5 \mathrm{a}$ & $7.1 \mathrm{a}$ & $2.16 \mathrm{a}$ & $11.49 \mathrm{a}$ & $8.60 a b$ & 759 a & $10,232 a$ \\
\hline Kataguruma & $108.9 \mathrm{c}$ & $15.6 \mathrm{a}$ & $7.0 \mathrm{a}$ & $2.21 \mathrm{a}$ & $11.18 \mathrm{a}$ & $8.83 \mathrm{a}$ & 779 a & 9,550 a \\
\hline Konesianhot & $116.1 \mathrm{a}$ & $15.7 \mathrm{a}$ & $7.5 \mathrm{a}$ & $2.23 \mathrm{a}$ & $12.34 \mathrm{a}$ & $8.52 \mathrm{ab}$ & 765 a & $9,913 \mathrm{a}$ \\
\hline Koregon PR-380 & $111.8 \mathrm{bc}$ & $15.4 \mathrm{a}$ & $7.3 \mathrm{a}$ & $2.24 \mathrm{a}$ & $11.45 \mathrm{a}$ & $8.94 \mathrm{a}$ & 752 a & $10,060 \mathrm{a}$ \\
\hline PR-power & $111.1 \mathrm{bc}$ & $15.3 \mathrm{a}$ & $7.3 \mathrm{a}$ & $2.32 \mathrm{a}$ & $11.38 \mathrm{a}$ & $8.14 b$ & 763 a & 9,582 a \\
\hline Tantan & $113.8 a b$ & $15.3 \mathrm{a}$ & $7.5 \mathrm{a}$ & $2.23 \mathrm{a}$ & $11.59 \mathrm{a}$ & $8.53 a b$ & $770 \mathrm{a}$ & 9,879 a \\
\hline \multicolumn{9}{|l|}{ Third harvest } \\
\hline Non-graft & $118.7 a b$ & $15.3 \mathrm{a}$ & $7.8 \mathrm{a}$ & $2.24 \mathrm{a}$ & $11.91 \mathrm{c}$ & $10.91 \mathrm{c}$ & 888 a & $8,354 a$ \\
\hline Auto-graft & $117.6 \mathrm{ab}$ & $15.5 \mathrm{a}$ & $7.6 \mathrm{a}$ & $2.15 \mathrm{a}$ & $12.26 \mathrm{bc}$ & $10.17 \mathrm{c}$ & $937 a$ & $7,723 a$ \\
\hline Kataguruma & $116.9 b$ & $15.5 \mathrm{a}$ & $7.6 \mathrm{a}$ & $2.17 \mathrm{a}$ & $12.13 \mathrm{bc}$ & $11.81 a b$ & 980 a & $9,571 \mathrm{a}$ \\
\hline Konesianhot & $122.4 \mathrm{a}$ & 15.9 a & $7.7 \mathrm{a}$ & $2.25 \mathrm{a}$ & $13.99 \mathrm{a}$ & $10.25 \mathrm{c}$ & 908 a & $7,710 a$ \\
\hline Koregon PR-380 & $113.8 b$ & $15.3 \mathrm{a}$ & $7.5 \mathrm{a}$ & $2.12 \mathrm{a}$ & $11.98 \mathrm{c}$ & $12.08 \mathrm{a}$ & 953 a & $8,248 a$ \\
\hline PR-power & $117.5 \mathrm{ab}$ & $15.3 \mathrm{a}$ & $7.7 \mathrm{a}$ & $2.11 \mathrm{a}$ & $13.03 \mathrm{~b}$ & $10.37 \mathrm{c}$ & $1,120 \mathrm{a}$ & $9,868 \mathrm{a}$ \\
\hline Tantan & $118.0 \mathrm{ab}$ & $15.4 a$ & $7.7 \mathrm{a}$ & $2.17 \mathrm{a}$ & $12.88 \mathrm{bc}$ & $11.06 \mathrm{bc}$ & 940 a & 7,947 a \\
\hline \multicolumn{9}{|l|}{$P$ value } \\
\hline Rootstock (A) & $<0.0001$ & 0.0739 & 0.0872 & 0.6882 & $<0.0001$ & $<0.0001$ & 0.3875 & 0.7626 \\
\hline Harvest time $(B)$ & 0.1033 & $<0.0001$ & 0.0007 & $<0.0001$ & 0.0002 & 0.0010 & 0.0008 & 0.1878 \\
\hline$A \times B$ & 0.3274 & 0.8355 & 0.4222 & 0.0742 & 0.0625 & $<0.0001$ & 0.0538 & 0.1648 \\
\hline
\end{tabular}

${ }^{\mathrm{z}}$ Fruit shape index $=$ fruit width/fruit length.

${ }^{\mathrm{y}}$ Inretarding culture, first, second, and third harvest were done on December 5, January 9, and February 20, respectively.

'Mean separation within columns for each harvest time by Duncan's multiple range test $(P \leq 0.05)$.

\section{Discussion}

The fruit quality of vegetables including appearance, firmness, texture, flavor, and health-related compounds of the product is affected by cultivar genotype, environmental conditions (light, temperature, humidity, and atmospheric $\mathrm{CO}_{2}$ ), and agricultural practices such as water management, fertilization strategies, growth and development regulators, pruning, growing systems, harvesting stage, and grafting (Rouphael et al., 2010). There are several conflicting reports on changes in fruit quality due to grafting and whether grafting effects are advantageous or disadvantageous (Davis et al., 2008a, 2008b; Flores et al., 2010).

Positive effects of grafting are reported in tomato and watermelon, including the increase of fruit size, firmness, total soluble solids (TSS) content, and titratable acidity (Flores et al., 2010; Miguel et al., 2004). On the contrary, other reports showed abnormal fruit quality by grafting in eggplant, melon, and watermelon, including poor texture, reduction of contents of TSS and vitamin C and firmness (Arvanitoyannis et al., 2005; Lee and Oda, 2003; Traka-Mavrona et al., 2000). There were also reports that demonstrated that grafting had 
Table 4. Effects of different rootstocks on the apparent quality and textural property of 'Saengsaeng' pepper fruits at different harvest time in semi-forcing culture.

\begin{tabular}{|c|c|c|c|c|c|c|c|c|}
\hline \multirow[b]{2}{*}{ Rootstock } & \multicolumn{6}{|c|}{ Fruit quality } & \multicolumn{2}{|c|}{ Textural property } \\
\hline & $\begin{array}{c}\text { Fruit } \\
\text { length } \\
(\mathrm{mm})\end{array}$ & $\begin{array}{l}\text { Fruit } \\
\text { width } \\
(\mathrm{mm})\end{array}$ & $\begin{array}{c}\text { Fruit } \\
\text { shape } \\
\text { index }\end{array}$ & $\begin{array}{c}\text { Flesh } \\
\text { thickness } \\
(\mathrm{mm})\end{array}$ & $\begin{array}{l}\text { Fruit } \\
\text { weight } \\
(\mathrm{g})\end{array}$ & $\begin{array}{c}\text { Dry } \\
\text { matter } \\
(\%)\end{array}$ & $\begin{array}{l}\text { Hardness } \\
\left(\mathrm{kN} \cdot \mathrm{m}^{-2}\right)\end{array}$ & $\begin{array}{l}\text { Strength } \\
\left(\mathrm{kN} \cdot \mathrm{m}^{-2}\right)\end{array}$ \\
\hline \multicolumn{9}{|l|}{ First harvest ${ }^{y}$} \\
\hline Auto-graft & $99.9 \mathrm{a}^{\mathrm{x}}$ & $14.1 \mathrm{a}$ & $7.1 \mathrm{a}$ & $1.53 \mathrm{a}$ & $4.26 \mathrm{a}$ & - & 394 a & $3,987 a$ \\
\hline Kataguruma & 102.9 a & $14.4 \mathrm{a}$ & $7.2 \mathrm{a}$ & $1.36 \mathrm{a}$ & $4.50 \mathrm{a}$ & - & $407 a$ & $3,940 a$ \\
\hline Konesianhot & $100.4 \mathrm{a}$ & $14.5 \mathrm{a}$ & $6.9 \mathrm{a}$ & $1.72 \mathrm{a}$ & $4.39 \mathrm{a}$ & - & $401 \mathrm{a}$ & 3,731 a \\
\hline Koregon PR-380 & $100.8 \mathrm{a}$ & 13.9 a & $7.3 \mathrm{a}$ & $1.48 \mathrm{a}$ & $4.28 \mathrm{a}$ & - & 379 a & 3,451 a \\
\hline PR-power & 98.3 a & $14.3 \mathrm{a}$ & 6.9 a & $1.59 \mathrm{a}$ & $4.46 \mathrm{a}$ & - & 372 a & 3,084 a \\
\hline Tantan & $102.4 \mathrm{a}$ & $14.1 \mathrm{a}$ & $7.3 \mathrm{a}$ & $1.55 \mathrm{a}$ & $4.55 a$ & - & $419 a$ & 3,587 a \\
\hline \multicolumn{9}{|l|}{ Second harvest } \\
\hline Auto-graft & $93.8 \mathrm{a}$ & $12.0 \mathrm{a}$ & 7.9 a & $1.11 \mathrm{a}$ & $5.25 \mathrm{a}$ & $8.81 \mathrm{a}$ & $439 a b$ & $4,320 \mathrm{a}$ \\
\hline Kataguruma & $94.0 \mathrm{a}$ & $12.1 \mathrm{a}$ & $7.8 \mathrm{a}$ & $1.04 \mathrm{a}$ & $4.67 \mathrm{~b}$ & $8.71 \mathrm{a}$ & $450 a b$ & $4,426 a$ \\
\hline Konesianhot & 96.0 a & $12.4 \mathrm{a}$ & $7.8 \mathrm{a}$ & $1.05 \mathrm{a}$ & $5.39 \mathrm{a}$ & $9.14 \mathrm{a}$ & 468 a & $4,446 a$ \\
\hline Koregon PR-380 & 93.4 a & $12.2 \mathrm{a}$ & $7.7 \mathrm{a}$ & 0.99 a & $4.97 \mathrm{ab}$ & 8.95 a & $482 a$ & 4,463 a \\
\hline PR-power & $92.4 \mathrm{a}$ & $12.0 \mathrm{a}$ & $7.7 \mathrm{a}$ & $1.00 \mathrm{a}$ & $4.96 a b$ & 8.81 a & $439 a b$ & $4,335 a$ \\
\hline Tantan & 95.3 a & $11.8 \mathrm{a}$ & $8.2 \mathrm{a}$ & $1.10 \mathrm{a}$ & $5.30 \mathrm{a}$ & $8.83 a$ & $414 \mathrm{~b}$ & $4,238 a$ \\
\hline \multicolumn{9}{|l|}{ Third harvest } \\
\hline Auto-graft & $97.5 \mathrm{a}$ & $12.5 \mathrm{ab}$ & $7.9 a b$ & $1.65 \mathrm{a}$ & $5.03 \mathrm{a}$ & $9.05 a b$ & 529 a & $4,841 \mathrm{a}$ \\
\hline Kataguruma & $97.0 \mathrm{a}$ & $12.2 \mathrm{a}-\mathrm{c}$ & $8.0 \mathrm{ab}$ & $1.51 \mathrm{a}$ & $5.03 a$ & $9.01 \mathrm{ab}$ & 536 a & $5,026 a$ \\
\hline Konesianhot & $98.4 \mathrm{a}$ & $11.8 \mathrm{c}$ & $8.4 \mathrm{a}$ & $1.58 \mathrm{a}$ & 4.78 a & 8.72 bc & $488 a$ & $5,012 a$ \\
\hline Koregon PR-380 & 97.2 a & $12.4 \mathrm{ab}$ & $7.9 a b$ & $1.55 \mathrm{a}$ & 5.10 a & $8.56 \mathrm{bc}$ & $503 a$ & 4,794 a \\
\hline PR-power & 98.2 a & $12.0 \mathrm{bc}$ & $8.2 \mathrm{a}$ & $1.52 \mathrm{a}$ & $4.90 \mathrm{a}$ & 9.50 a & 497 a & $5,055 a$ \\
\hline Tantan & $97.0 \mathrm{a}$ & $12.8 \mathrm{a}$ & $7.7 \mathrm{~b}$ & $1.53 a$ & $5.23 \mathrm{a}$ & $8.04 \mathrm{c}$ & 509 a & 4,567 a \\
\hline \multicolumn{9}{|l|}{$P$ value } \\
\hline Rootstock (A) & 0.3572 & 0.9769 & 0.9299 & 0.1085 & 0.0926 & 0.0141 & 0.4004 & 0.4074 \\
\hline Harvest time (B) & 0.1236 & 0.0001 & 0.0118 & 0.0038 & 0.0448 & 0.8304 & 0.0014 & $<0.0001$ \\
\hline$A \times B$ & 0.5305 & 0.0047 & 0.0048 & 0.4052 & 0.0095 & 0.0020 & 0.0456 & 0.5569 \\
\hline
\end{tabular}

${ }^{\mathrm{z}}$ Fruit shape index $=$ fruit width/fruit length.

${ }^{y}$ In semi-forcing culture, first, second, and third harvest were done on June 12, July 10, and August 14, respectively.

${ }^{x}$ Mean separation within columns for each harvest time by Duncan's multiple range test $(P \leq 0.05)$.

no effect on fruit shape index, thickness of rind, texture, lycopene content or TSS in cucumber, tomato, and watermelon (Alan et al., 2007; Khah et al., 2006; Sakata et al., 2008).

In this study, the yield and fruit qualities of three pepper varieties grafted onto different rootstocks were investigated during two harvest periods (semi-forcing culture and retarding culture). Total marketable yield was not significantly influenced by either auto-grafting or grafting with the five commercial rootsctocks. In contrast, the fruit quality (fruit size, weight, flesh thickness) and textural property were influenced by grafting with different rootstocks (Tables 1, 2, 3, 4, 5, 6, and 7). However, fruit quality parameters were affected by grafting with different scion varieties, harvest periods, and harvest time. In the case of 'Nokkwang', fruit length, weight, flesh thickness, and dry matter were affected by grafting, while those differed depending on harvest period and time. In the case of 'Saengsaeng Matkkwari', the fruit width, weight, and dry matter in semi-forcing culture were affected by grafting, whereas fruit shape index and flesh thickness in addition to those were also influenced by grafting in retarding culture. In the case of 'Shinhong', fruit length, flesh thickness, weight, and dry matter in semi-forcing culture and fruit length and weight in retarding culture were affected by grafting. Regarding the textural property, the hardness of 'Nokkwang' pepper fruit in the semi-forcing culture was affected by grafting.

Tsaballa et al. (2013) reported that grafting the round shaped pepper (scion) on the long shaped pepper (rootstock) 
Table 5. Effects of different rootstocks on the apparent quality and textural property of 'Saengsaeng' pepper fruits at different harvest time inretarding culture.

\begin{tabular}{|c|c|c|c|c|c|c|c|c|}
\hline \multirow[b]{2}{*}{ Rootstock } & \multicolumn{6}{|c|}{ Fruit quality } & \multicolumn{2}{|c|}{ Textural property } \\
\hline & $\begin{array}{l}\text { Fruit } \\
\text { length } \\
(\mathrm{mm})\end{array}$ & $\begin{array}{l}\text { Fruit } \\
\text { width } \\
(\mathrm{mm})\end{array}$ & $\begin{array}{l}\text { Fruit } \\
\text { shape } \\
\text { index }^{z}\end{array}$ & $\begin{array}{c}\text { Flesh } \\
\text { thickness } \\
(\mathrm{mm})\end{array}$ & $\begin{array}{l}\text { Fruit } \\
\text { weight } \\
\text { (g) }\end{array}$ & $\begin{array}{c}\text { Dry } \\
\text { matter } \\
(\%)\end{array}$ & $\begin{array}{l}\text { Hardness } \\
\left(\mathrm{kN} \cdot \mathrm{m}^{-2}\right)\end{array}$ & $\begin{array}{l}\text { Strength } \\
\left(\mathrm{kN} \cdot \mathrm{m}^{-2}\right)\end{array}$ \\
\hline \multicolumn{9}{|l|}{ First harvest ${ }^{y}$} \\
\hline Non-graft & $85.7 a^{x}$ & $10.4 \mathrm{bc}$ & $8.3 \mathrm{a}$ & $0.81 \mathrm{a}$ & $3.42 b$ & 9.91 a & $329 a$ & $2,932 a$ \\
\hline Auto-graft & $84.1 \mathrm{a}$ & $10.7 \mathrm{bc}$ & $7.9 a b$ & $0.79 \mathrm{a}$ & $3.54 \mathrm{ab}$ & 9.82 a & $350 \mathrm{a}$ & $3,055 \mathrm{a}$ \\
\hline Kataguruma & $84.0 \mathrm{a}$ & $11.2 a b$ & $7.5 \mathrm{~b}-\mathrm{d}$ & $0.73 \mathrm{a}$ & $3.72 a b$ & $9.96 \mathrm{a}$ & 345 a & $3,266 a$ \\
\hline Konesianhot & $81.7 \mathrm{a}$ & $11.0 \mathrm{ab}$ & $7.4 \mathrm{~cd}$ & $0.77 \mathrm{a}$ & $3.38 \mathrm{~b}$ & $9.98 \mathrm{a}$ & 313 a & $2,909 a$ \\
\hline Koregon PR-380 & 84.6 a & $11.3 \mathrm{a}$ & $7.5 \mathrm{~b}-\mathrm{d}$ & $0.73 \mathrm{a}$ & $3.93 \mathrm{a}$ & $9.87 \mathrm{a}$ & 332 a & $2,917 a$ \\
\hline PR-power & $81.7 \mathrm{a}$ & $11.3 \mathrm{a}$ & $7.3 \mathrm{~d}$ & $0.77 \mathrm{a}$ & $3.59 a b$ & $9.85 \mathrm{a}$ & 328 a & $3,033 a$ \\
\hline Tantan & $84.3 \mathrm{a}$ & 10.8 a-c & $7.8 \mathrm{bc}$ & $0.71 \mathrm{a}$ & $3.68 \mathrm{ab}$ & $9.58 \mathrm{a}$ & 322 a & $2,809 a$ \\
\hline \multicolumn{9}{|l|}{ Second harvest } \\
\hline Non-graft & $77.4 \mathrm{a}$ & 11.4 b-d & $6.8 \mathrm{a}$ & $1.30 \mathrm{~b}$ & $3.73 \mathrm{a}$ & $9.90 \mathrm{~b}$ & 392 a & $2,923 \mathrm{a}$ \\
\hline Auto-graft & 74.2 a & $11.1 \mathrm{~cd}$ & $6.7 \mathrm{a}$ & $1.52 \mathrm{a}$ & $3.53 \mathrm{a}$ & $9.96 \mathrm{~b}$ & 393 a & $3,062 \mathrm{a}$ \\
\hline Kataguruma & 75.2 a & 11.5 a-d & $6.6 \mathrm{a}$ & $1.62 \mathrm{a}$ & $3.54 \mathrm{a}$ & $10.25 a b$ & $383 a$ & $2,927 a$ \\
\hline Konesianhot & 75.2 a & $11.5 \mathrm{a}-\mathrm{c}$ & $6.6 \mathrm{a}$ & $1.52 \mathrm{a}$ & $3.69 a$ & $10.65 \mathrm{a}$ & 362 a & $2,459 a$ \\
\hline Koregon PR-380 & 76.5 a & $11.8 a b$ & $6.5 \mathrm{a}$ & $1.40 a b$ & $3.60 \mathrm{a}$ & $10.43 a b$ & 372 a & $2,833 a$ \\
\hline PR-power & $74.8 \mathrm{a}$ & $12.0 \mathrm{a}$ & $6.3 \mathrm{a}$ & $1.52 \mathrm{a}$ & $3.61 \mathrm{a}$ & $10.49 a b$ & 427 a & $3,184 a$ \\
\hline Tantan & 73.9 a & $11.0 \mathrm{~d}$ & $6.8 \mathrm{a}$ & $1.45 a b$ & $3.34 \mathrm{a}$ & $10.49 a b$ & 347 a & $2,631 \mathrm{a}$ \\
\hline \multicolumn{9}{|l|}{ Third harvest } \\
\hline Non-graft & 83.6 a & $11.5 \mathrm{a}$ & $7.3 \mathrm{a}$ & $1.40 \mathrm{a}$ & $4.13 \mathrm{a}$ & $11.62 \mathrm{a}$ & $453 a$ & $3,977 a$ \\
\hline Auto-graft & $84.2 \mathrm{a}$ & $11.9 \mathrm{a}$ & $7.1 \mathrm{a}$ & $1.32 \mathrm{a}$ & $4.23 \mathrm{a}$ & $11.34 \mathrm{a}$ & $460 a$ & $4,842 a$ \\
\hline Kataguruma & 78.7 a & $11.7 \mathrm{a}$ & $6.8 \mathrm{a}$ & $1.28 \mathrm{a}$ & $3.77 \mathrm{a}$ & $12.41 \mathrm{a}$ & $450 \mathrm{a}$ & $4,472 \mathrm{a}$ \\
\hline Konesianhot & $80.2 \mathrm{a}$ & $12.4 \mathrm{a}$ & $6.5 \mathrm{a}$ & $1.32 \mathrm{a}$ & $4.09 \mathrm{a}$ & $12.19 \mathrm{a}$ & 415 a & $4,348 a$ \\
\hline Koregon PR-380 & 80.9 a & $11.9 \mathrm{a}$ & $6.8 \mathrm{a}$ & $1.26 \mathrm{a}$ & $3.94 \mathrm{a}$ & $12.16 \mathrm{a}$ & 449 a & $4,949 a$ \\
\hline PR-power & $83.4 \mathrm{a}$ & $12.0 \mathrm{a}$ & $7.0 \mathrm{a}$ & $1.41 \mathrm{a}$ & $4.24 \mathrm{a}$ & $11.10 \mathrm{a}$ & 438 a & $4,687 \mathrm{a}$ \\
\hline Tantan & 83.7 a & $12.1 \mathrm{a}$ & $6.9 \mathrm{a}$ & $1.39 a$ & $4.17 \mathrm{a}$ & $11.70 \mathrm{a}$ & 448 a & $4,394 a$ \\
\hline \multicolumn{9}{|l|}{$\mathrm{P}$ value } \\
\hline Rootstock (A) & 0.0427 & $<0.0001$ & $<0.0001$ & 0.0920 & 0.7234 & 0.0123 & 0.2898 & 0.2635 \\
\hline Harvest time $(B)$ & 0.0036 & 0.0141 & 0.0002 & 0.0002 & 0.0059 & 0.0947 & 0.0005 & 0.0029 \\
\hline$A \times B$ & 0.1005 & 0.0089 & 0.0549 & 0.0004 & 0.0014 & 0.1207 & 0.9185 & 0.8613 \\
\hline
\end{tabular}

${ }^{\mathrm{z}}$ Fruit shape index $=$ fruit width/fruit length.

${ }^{y}$ In retarding culture, first, second, and third harvest were done on December 10, January 7, and February 18, respectively.

'Mean separation within columns for each harvest time by Duncan's multiple range test $(P \leq 0.05)$.

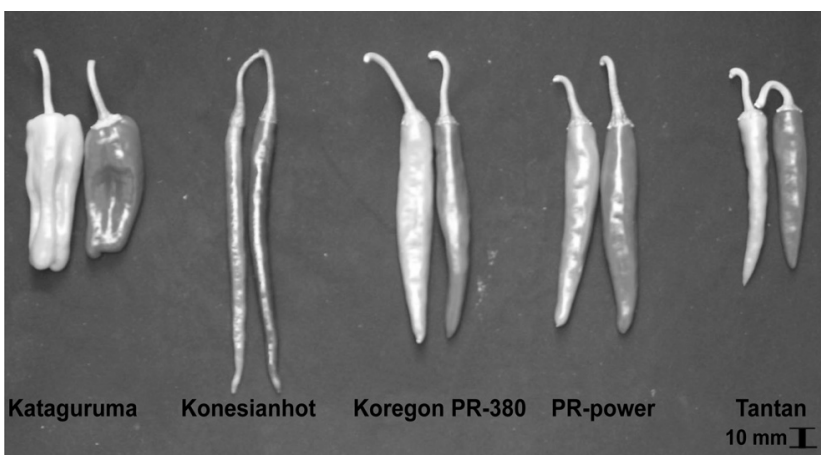

Fig. 3. Fruit shapes of different rootstock genotypes. changed the fruit shape of the scion, giving rise to elongated fruits different from the normal round shape fruit expected in the scion. Among the rootstocks used in this experiment, the fruit of 'Konesianhot' was slender with a pointed apex and the fruit length was the longest $(118.8 \mathrm{~mm})$ (Table 8 and Fig. 3). The fruit of 'Kataguruma' was bell pepper type with inverted-blunt and two-lobed apex. Its fruit was shortest $(80.0 \mathrm{~mm})$, but widest $(24.8 \mathrm{~mm})$. The fruit length of 'Tantan' $(83.6 \mathrm{~mm})$ was shorter than that of 'Koregon PR-380' (95.6 mm). The highest fruit weight was recorded in 'Kataguruma' and the lowest in 'Konesianhot'. In the 
Table 6. Effects of different rootstocks on the apparent quality and textural property of 'Shinhong' pepper fruits at different harvest time semi-forcing culture.

\begin{tabular}{|c|c|c|c|c|c|c|c|c|}
\hline \multirow[b]{2}{*}{ Rootstock } & \multicolumn{6}{|c|}{ Fruit quality } & \multicolumn{2}{|c|}{ Textural property } \\
\hline & $\begin{array}{c}\text { Fruit } \\
\text { length } \\
(\mathrm{mm})\end{array}$ & $\begin{array}{l}\text { Fruit } \\
\text { width } \\
(\mathrm{mm})\end{array}$ & $\begin{array}{c}\text { Fruit } \\
\text { shape } \\
\text { index }\end{array}$ & $\begin{array}{c}\text { Flesh } \\
\text { thickness } \\
\quad(\mathrm{mm})\end{array}$ & $\begin{array}{c}\text { Fruit } \\
\text { weight } \\
\text { (g) }\end{array}$ & $\begin{array}{c}\text { Dry } \\
\text { matter } \\
(\%)\end{array}$ & $\begin{array}{l}\text { Hardness } \\
\left(\mathrm{kN} \cdot \mathrm{m}^{-2}\right)\end{array}$ & $\begin{array}{l}\text { Strength } \\
\left(\mathrm{kN} \cdot \mathrm{m}^{-2}\right)\end{array}$ \\
\hline \multicolumn{9}{|l|}{ First harvest $^{y}$} \\
\hline Auto-graft & $96.7 a b^{x}$ & $12.0 \mathrm{~b}$ & $8.1 \mathrm{a}$ & $1.49 \mathrm{~b}$ & $6.27 a b$ & $8.49 \mathrm{c}$ & 533 a & $5,552 a b$ \\
\hline Kataguruma & $94.2 \mathrm{~b}$ & $12.0 \mathrm{~b}$ & 7.9 a & $1.74 \mathrm{a}$ & $6.66 \mathrm{a}$ & $8.55 \mathrm{c}$ & 505 a & $4,766 \mathrm{c}$ \\
\hline Konesianhot & $93.3 \mathrm{~b}$ & $12.0 \mathrm{~b}$ & $7.8 \mathrm{a}$ & $1.76 \mathrm{a}$ & $5.92 \mathrm{~b}$ & $10.05 \mathrm{a}$ & 538 a & 5,787 a \\
\hline Koregon PR-380 & 99.4 a & $12.5 \mathrm{ab}$ & $8.0 \mathrm{a}$ & $1.54 b$ & $6.90 \mathrm{a}$ & $8.40 \mathrm{c}$ & 478 a & $4,740 \mathrm{c}$ \\
\hline PR-power & $96.6 \mathrm{ab}$ & $12.7 \mathrm{a}$ & $7.7 \mathrm{a}$ & $1.52 b$ & $6.52 a b$ & 8.91 bc & 517 a & $4,923 \mathrm{bc}$ \\
\hline Tantan & $96.9 \mathrm{ab}$ & $12.1 \mathrm{~b}$ & $8.0 \mathrm{a}$ & $1.51 \mathrm{~b}$ & $6.19 a b$ & $9.92 a b$ & 504 a & $4,878 \mathrm{bc}$ \\
\hline \multicolumn{9}{|l|}{ Second harvest } \\
\hline Auto-graft & $86.7 \mathrm{a}$ & $14.1 \mathrm{a}$ & $6.2 \mathrm{a}$ & $1.99 b$ & $6.38 \mathrm{a}$ & $11.16 \mathrm{a}$ & 541 a & 5,298 a \\
\hline Kataguruma & 89.5 a & $14.5 \mathrm{a}$ & $6.2 \mathrm{a}$ & $1.98 b$ & $6.39 \mathrm{a}$ & 10.62 a & 528 a & 5,332 a \\
\hline Konesianhot & 88.1 a & $14.6 \mathrm{a}$ & $6.0 \mathrm{a}$ & $1.89 \mathrm{~b}$ & $6.21 \mathrm{a}$ & $11.11 \mathrm{a}$ & 495 a & $4,910 \mathrm{a}$ \\
\hline Koregon PR-380 & 85.5 a & $14.2 \mathrm{a}$ & $6.1 \mathrm{a}$ & $1.97 b$ & $5.95 \mathrm{a}$ & $10.46 a$ & $513 a$ & 5,401 a \\
\hline PR-power & $87.5 \mathrm{a}$ & $14.4 \mathrm{a}$ & $6.1 \mathrm{a}$ & $2.20 \mathrm{a}$ & $6.43 \mathrm{a}$ & $10.73 a$ & 517 a & $5,151 \mathrm{a}$ \\
\hline Tantan & 89.8 a & $14.9 \mathrm{a}$ & $6.1 \mathrm{a}$ & $1.88 b$ & $6.47 \mathrm{a}$ & $10.91 \mathrm{a}$ & 521 a & 5,097 a \\
\hline \multicolumn{9}{|l|}{ Third harvest } \\
\hline Auto-graft & 83.9 a & $11.7 \mathrm{a}$ & $7.2 \mathrm{a}$ & $1.78 \mathrm{a}$ & $5.33 a$ & $12.51 \mathrm{a}$ & $460 \mathrm{a}$ & 5,226 a \\
\hline Kataguruma & 86.7 a & $11.4 \mathrm{a}$ & $7.7 \mathrm{a}$ & $1.90 \mathrm{a}$ & $5.43 \mathrm{a}$ & $11.96 \mathrm{a}$ & 503 a & 5,229 a \\
\hline Konesianhot & 85.1 a & 11.6 a & $7.4 \mathrm{a}$ & $1.76 \mathrm{a}$ & $5.36 \mathrm{a}$ & $12.35 \mathrm{a}$ & 463 a & 5,025 a \\
\hline Koregon PR-380 & 84.7 a & $11.5 \mathrm{a}$ & $7.4 \mathrm{a}$ & $1.76 a$ & $5.41 \mathrm{a}$ & $12.84 \mathrm{a}$ & 471 a & 5,143 a \\
\hline PR-power & $83.4 \mathrm{a}$ & $11.4 \mathrm{a}$ & $7.4 \mathrm{a}$ & $1.80 \mathrm{a}$ & $5.28 \mathrm{a}$ & $11.42 \mathrm{a}$ & 485 a & 5,102 a \\
\hline Tantan & 86.3 a & $12.0 \mathrm{a}$ & $7.3 \mathrm{a}$ & $1.76 \mathrm{a}$ & $5.62 \mathrm{a}$ & $11.88 \mathrm{a}$ & 473 a & 4,960 a \\
\hline \multicolumn{9}{|l|}{$\mathrm{P}$ value } \\
\hline Rootstock (A) & 0.2694 & 0.2397 & 0.3095 & 0.0015 & 0.4632 & 0.0353 & 0.3686 & 0.2682 \\
\hline Harvest time (B) & 0.0306 & 0.0005 & $<0.0001$ & 0.0051 & 0.0563 & 0.0004 & 0.1541 & 0.7065 \\
\hline$A \times B$ & 0.0129 & 0.0791 & 0.2258 & $<0.0001$ & 0.1133 & 0.0121 & 0.0379 & 0.0208 \\
\hline
\end{tabular}

${ }^{\mathrm{z}}$ Fruit shape index $=$ fruit width/fruit length.

${ }^{y}$ In semi-forcing culture, first, second, and third harvest were done on June 27, July 26, and August 8 , respectively.

'Mean separation within columns for each harvest time by Duncan's multiple range test $(P \leq 0.05)$.

case of 'Nokkwang', however, the fruit length of grafted peppers had no difference among rootstocks or the fruits of non-graft and auto-graft were the longest in semi-forcing culture, though the fruit of grafted onto 'Konesianhot' was the longest $(118.5 \mathrm{~mm})$ in retarding culture. The fruit length of 'Saengsaeng Matkkwari' or 'Shinhong' grafted onto 'Konesianhot' was also shorter or similar than that of non-grafted pepper. Accordingly, it is considered that grafting affects the fruit quality, but the fruit characteristics of rootstock do not affect the fruit characteristics of scion grafted onto that rootstock (Tables 2, 3, 4, 5, 6, 7, and Fig. 4).

There were reports that fruit length and weight of 'Bugang' and 'Geumtap' decreased for later harvest time (Cho et al., 2004). In this study, fruit quality of 'Nokkwang' in semi-force culture was consistent with that report. However, in retarding culture, fruit length was not affected by harvest time and fruit weight increased for later harvest time (Tables 2 and 3). The fruit quality of 'Saengsaeng Matkkwari' and 'Shinhong' was also different according to harvest time and harvest pattern (Tables 4, 5, 6, and 7). The differences in fruit quality by grafting may be attributable partly to different production environments (e.g. light intensity, air temperature, vapor pressure deficit) and methods (e.g. soilless vs. soil culture, irrigation, and fertilization), type of rootstock/scion combinations used, rootstock/scion incompatibility, and harvest time (Davis et al., 2008b; Lee et al., 2010; Rouphael et al., 2010; Zhao et al., 2011). Exposure to high temperature often causes the reduction of yield and quality of many crops including vegetables 


\begin{tabular}{|c|c|c|c|c|c|c|c|}
\hline $\begin{array}{l}\text { Rootstock } \\
\text { Scion }\end{array}$ & Non-graft & Auto-graft & Kataguruma & Konesianhot & Koregon PR-380 & PR-power & Tantan \\
\hline Nokkwang & & & & & & & \\
\hline Saengsaeng & & & & & & 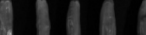 & \\
\hline Shinhong & & & & & & & \\
\hline
\end{tabular}

Fig. 4. Fruits of peppers 'Nokkwang', 'Saensaeng', and 'Shinhong' grafted onto different rootstocks from third harvest of retarding culture.

Table 7. Effects of different rootstocks on the apparent quality and textural property of 'Shinhong' pepper fruits at different harvest time inretarding culture.

\begin{tabular}{|c|c|c|c|c|c|c|c|c|}
\hline \multirow[b]{2}{*}{ Rootstock } & \multicolumn{6}{|c|}{ Fruit quality } & \multicolumn{2}{|c|}{ Textural property } \\
\hline & $\begin{array}{c}\text { Fruit } \\
\text { length } \\
(\mathrm{mm})\end{array}$ & $\begin{array}{l}\text { Fruit } \\
\text { width } \\
(\mathrm{mm})\end{array}$ & $\begin{array}{c}\text { Fruit } \\
\text { shape } \\
\text { index }\end{array}$ & $\begin{array}{c}\text { Flesh } \\
\text { thickness } \\
(\mathrm{mm})\end{array}$ & $\begin{array}{c}\text { Fruit } \\
\text { weight } \\
\text { (g) }\end{array}$ & $\begin{array}{c}\text { Dry } \\
\text { matter } \\
(\%)\end{array}$ & $\begin{array}{l}\text { Hardness } \\
\left(\mathrm{kN} \cdot \mathrm{m}^{-2}\right)\end{array}$ & $\begin{array}{l}\text { Strength } \\
\left(\mathrm{kN} \cdot \mathrm{m}^{-2}\right)\end{array}$ \\
\hline \multicolumn{9}{|l|}{ First harvest $^{y}$} \\
\hline Non-graft & $72.5 a^{x}$ & $10.6 \mathrm{a}$ & $6.8 \mathrm{a}$ & $1.62 \mathrm{a}$ & $3.79 \mathrm{a}$ & $9.87 \mathrm{a}$ & $413 a$ & $5,397 \mathrm{a}$ \\
\hline Auto-graft & $73.8 \mathrm{a}$ & $11.1 \mathrm{a}$ & $6.7 \mathrm{a}$ & $1.57 \mathrm{a}$ & $3.90 \mathrm{a}$ & 10.02 a & 416 a & $5,305 a$ \\
\hline Kataguruma & 70.9 a & 10.9 a & $6.5 \mathrm{a}$ & $1.55 \mathrm{a}$ & $3.57 \mathrm{a}$ & $9.81 \mathrm{a}$ & $426 a$ & $5,147 a$ \\
\hline Konesianhot & $72.2 \mathrm{a}$ & $10.8 \mathrm{a}$ & $6.7 \mathrm{a}$ & $1.54 \mathrm{a}$ & $3.69 \mathrm{a}$ & $9.81 \mathrm{a}$ & $413 a$ & $5,319 a$ \\
\hline Koregon PR-380 & 75.7 a & $11.2 \mathrm{a}$ & $6.8 \mathrm{a}$ & $1.56 \mathrm{a}$ & $4.12 \mathrm{a}$ & $9.88 \mathrm{a}$ & $413 a$ & $5,107 a$ \\
\hline PR-power & $75.1 \mathrm{a}$ & $11.2 \mathrm{a}$ & $6.7 \mathrm{a}$ & $1.55 \mathrm{a}$ & $4.10 \mathrm{a}$ & $10.06 \mathrm{a}$ & 436 a & $5,225 a$ \\
\hline Tantan & $72.3 \mathrm{a}$ & $10.8 \mathrm{a}$ & $6.8 \mathrm{a}$ & $1.49 \mathrm{a}$ & $3.72 \mathrm{a}$ & $9.93 \mathrm{a}$ & $368 \mathrm{~b}$ & $4,984 a$ \\
\hline \multicolumn{9}{|l|}{ Second harvest } \\
\hline Non-graft & $73.6 \mathrm{~b}$ & $11.2 \mathrm{a}$ & $6.6 \mathrm{a}$ & $1.46 \mathrm{a}$ & $4.10 \mathrm{c}$ & $10.09 \mathrm{a}$ & $405 a$ & $4,906 a$ \\
\hline Auto-graft & $76.5 \mathrm{a}$ & $11.5 \mathrm{a}$ & $6.7 \mathrm{a}$ & $1.54 \mathrm{a}$ & 4.39 a-c & $9.91 \mathrm{a}$ & $421 \mathrm{a}$ & $4,942 \mathrm{a}$ \\
\hline Kataguruma & $75.3 \mathrm{ab}$ & 11.6 a & $6.5 \mathrm{a}$ & $1.41 \mathrm{a}$ & $4.26 \mathrm{bc}$ & 10.12 a & $415 a$ & $5,133 a$ \\
\hline Konesianhot & $73.9 \mathrm{~b}$ & $11.5 \mathrm{a}$ & $6.5 \mathrm{a}$ & $1.55 \mathrm{a}$ & 4.35 a-c & $10.01 \mathrm{a}$ & $412 a$ & $5,290 a$ \\
\hline Koregon PR-380 & 77.7 a & $11.6 \mathrm{a}$ & $6.7 \mathrm{a}$ & $1.44 \mathrm{a}$ & $4.69 \mathrm{a}$ & $9.91 \mathrm{a}$ & 448 a & $4,795 a$ \\
\hline PR-power & 77.6 a & $11.3 \mathrm{a}$ & $6.9 \mathrm{a}$ & $1.43 \mathrm{a}$ & $4.54 a b$ & $10.27 \mathrm{a}$ & $400 \mathrm{a}$ & $4,534 a$ \\
\hline Tantan & 77.5 a & $11.6 \mathrm{a}$ & $6.7 \mathrm{a}$ & $1.57 \mathrm{a}$ & $4.57 \mathrm{ab}$ & 9.87 a & 440 a & 4,683 a \\
\hline \multicolumn{9}{|l|}{ Third harvest } \\
\hline Non-graft & $88.0 \mathrm{c}$ & 13.9 a & $6.4 \mathrm{a}$ & $2.05 \mathrm{a}$ & $7.02 \mathrm{a}$ & $12.42 \mathrm{a}$ & 616 a & $6,914 a$ \\
\hline Auto-graft & 88.8 a-c & 13.9 a & $6.4 \mathrm{a}$ & 1.99 a & $6.84 a$ & 11.79 a & 558 a & $6,419 a$ \\
\hline Kataguruma & $87.4 \mathrm{c}$ & $13.8 \mathrm{a}$ & $6.4 \mathrm{a}$ & $1.94 \mathrm{a}$ & $6.60 \mathrm{a}$ & 13.05 a & 575 a & $6,278 a$ \\
\hline Konesianhot & $87.9 \mathrm{c}$ & $13.8 \mathrm{a}$ & $6.4 \mathrm{a}$ & $1.88 \mathrm{a}$ & $6.91 \mathrm{a}$ & $12.42 \mathrm{a}$ & 574 a & $6,413 a$ \\
\hline Koregon PR-380 & 88.4 bc & $13.8 \mathrm{a}$ & $6.4 \mathrm{a}$ & $2.09 a$ & $6.58 \mathrm{a}$ & $12.42 \mathrm{a}$ & $633 a$ & $6,898 a$ \\
\hline PR-power & $92.0 \mathrm{a}$ & $14.1 \mathrm{a}$ & $6.5 \mathrm{a}$ & $2.05 \mathrm{a}$ & $7.10 \mathrm{a}$ & $11.73 \mathrm{a}$ & $585 a$ & $6,811 a$ \\
\hline Tantan & $91.5 \mathrm{ab}$ & $13.8 \mathrm{a}$ & $6.7 \mathrm{a}$ & $2.04 \mathrm{a}$ & $7.06 \mathrm{a}$ & $11.16 \mathrm{a}$ & 598 a & 7,322 a \\
\hline \multicolumn{9}{|l|}{$P$ value } \\
\hline Rootstock (A) & $<0.0001$ & 0.3549 & 0.1106 & 0.5794 & 0.0183 & 0.0040 & 0.2030 & 0.8916 \\
\hline Harvest time $(B)$ & $<0.0001$ & $<0.0001$ & 0.1739 & 0.0020 & $<0.0001$ & 0.0031 & 0.0007 & 0.0008 \\
\hline$A \times B$ & 0.4303 & 0.4964 & 0.8613 & 0.1511 & 0.0216 & $<0.0001$ & 0.0220 & 0.0454 \\
\hline
\end{tabular}

${ }^{\mathrm{z}}$ Fruit shape index $=$ fruit width/fruit length.

${ }^{y}$ In retarding culture, first, second, and third harvest were done on December 11, January 8, and February 19, respectively.

${ }^{\mathrm{x}}$ Mean separation within columns for each harvest time by Duncan's multiple range test $(P \leq 0.05)$. 
Table 8. The apparent quality of different rootstock genotypes.

\begin{tabular}{lccrr}
\hline \hline Rootstock & $\begin{array}{c}\text { Fruit length } \\
(\mathrm{mm})\end{array}$ & $\begin{array}{c}\text { Fruit width } \\
(\mathrm{mm})\end{array}$ & $\begin{array}{c}\text { Fruit shape } \\
\text { index }\end{array}$ & $\begin{array}{c}\text { Fruit weight } \\
(\mathrm{g})\end{array}$ \\
\hline Kataguruma & $80.0 \mathrm{c}^{\mathrm{y}}$ & $24.8 \mathrm{a}$ & $3.3 \mathrm{~d}$ & $13.7 \mathrm{a}$ \\
Konesianhot & $118.8 \mathrm{a}$ & $8.3 \mathrm{~d}$ & $14.5 \mathrm{a}$ & $5.0 \mathrm{e}$ \\
Koregon PR-380 & $95.6 \mathrm{~b}$ & $15.0 \mathrm{c}$ & $6.4 \mathrm{~b}$ & $8.6 \mathrm{c}$ \\
PR-power & $88.0 \mathrm{bc}$ & $18.1 \mathrm{~b}$ & $4.9 \mathrm{c}$ & $10.3 \mathrm{~b}$ \\
Tantan & $83.6 \mathrm{c}$ & $14.5 \mathrm{c}$ & $5.8 \mathrm{bc}$ & $6.7 \mathrm{~d}$ \\
\hline
\end{tabular}

${ }^{\mathrm{z}}$ Fruit shape index $=$ fruit width/fruit length.

${ }^{y}$ Mean separation within columns for each harvest time by Duncan's multiple range test $(P \leq 0.05)$.

(Erickson and Markhart, 2001; Firon et al., 2006). Temperature is the key factor in the development of pepper fruit and high temperature $\left(38 / 30^{\circ} \mathrm{C}\right.$ day/night) during the development of pepper fruit caused the poor quality including fruit size and weight (Pagamas and Nawata, 2008). Temperature and relative humidity condition were different between semi-forcing and retarding culture (Fig. 1). In semi-forcing culture, high temperature from late June was considered to be a reason for the decrease of fruit length and weight.

In semi-forcing culture, the cumulative yields of 'Nokkwang' and 'Saengsaeng Matkkwari' were similar (1,706 and 1,871 $\mathrm{g} /$ plant, respectively). However, the cumulative yield of 'Nokkwang' (1,036 g/plant) was greater than that of 'Saengsaeng Matkkwari' (709 g/plant) in retarding culture. 'Nokkwang' is known to be tolerant to low temperature (Lim et al., 2006) and each scion variety requires its own optimal environmental conditions. Rootstocks also have optimal temperature and moisture ranges (Davis et al., 2008a). Therefore, each rootstock/ scion combination may respond differently to environmental conditions such as temperature and relative humidity.

In conclusion, quality and textural property of pepper fruits were influenced by not only grafting with different rootstocksbut also harvest period and harvest time. Accordingly, rootstock/scion combination, the scion variety and the harvest period must be carefully chosen to get the desired optimal fruit quality.

\section{Literature Cited}

Alan, Ö., N. Özdemir, and Y. Günen. 2007. Effect of grafting on watermelon plant growth, yield and quality. J. Agronomy 6:362-365.

Arvanitoyannis, I.S., E.M. Khah, E.C. Christakou, and F.A. Bletos. 2005. Effect of grafting and modified atmosphere packaging on eggplant quality parameters during storage. Intl. J. Food Sci. Technol. 40:311-322.

Cho, B.C., K.W. Park, H.M. Kang, and H.K. Yun. 2004. Correlationship between climatic elements and external characteristics of red pepper fruit in different growing period. J. Bio-Environ. Control $13: 73-80$
Colla, G., Y. Rouphael, C. Leonardi, and Z. Bie. 2010. Role of grafting in vegetable crops grown under saline conditions. Scientia Hort. 127:147-155.

Davis, A.R., P. Perkins-Veazie, R. Hassell, A. Levi, S.R. King, and X. Zhang. 2008a. Grafting effects on vegetable quality. HortScience 43:1670-1672.

Davis, A.R., P. Perkins-Veazie, Y. Sakata, S. López-Galarza, J.V. Maroto, S.G. Lee, Y.C. Huh, Z. Sun, A. Miguel, S.R. King, R. Cohen, and J.M. Lee. 2008b. Cucurbit grafting. Critical Rev. Plant Sci. 27:50-74.

Erickson, A.N. and A.H. Markhart. 2001. Flower production, fruit set, and physiology of bell pepper during elevated temperature and vapor pressure deficit. J. Amer. Soc. Hort. Sci. 126:697-702.

Firon, N. R. Shaked, M.M. Peet, D.M. Pharr, E. Zamski, K. Resenfeld, L. Althan, and E. Pressman. 2006. Pollen grains of heat tolerant tomato cultivars retain higher carbohydrate concentration under stress conditions. Scientia Hort. 109:212-217.

Flores, F.B., P. Sanchez-Bel, M.T. Estañ, M.M. Martinez-Rodriguez, E. Moyano, B. Morales, J.F. Campos, J.O. Garcia-Abellan, M.I. Egea, N. Fernandez-Garcia, F. Romojaro, and M.C. Bolarin. 2010. The effectiveness of grafting to improve tomato fruit quality. Scientia Hort. 125:211-217.

Gisbert, C., P. Sánchez-Torres, M.D.Raigón, and F. Nueza. 2010. Phytophthora capsici resistance evaluation in pepper hybrids: Agronomic performance and fruit quality of pepper grafted plants. J. Food Agr. Environ. 8:116-121.

Khah, E.M., E. Kakava, A. Mavromatis, D. Chachalis, and C. Goulas. 2006. Effect of grafting on growth and yield of tomato (Lycopersicon esculentum Mill.) in greenhouse and open-field. J. Applied Hort. 8:3-7.

Lee, J. and M. Oda. 2003. Grafting of herbaceous vegetable and ornamental crops. Hort. Rev. 28:61-124.

Lee, J.M., C. Kubota, S.J. Tsao, Z. Bie, P. Hoyos Echevarria, L. Morra, and M. Oda. 2010. Current status of vegetable grafting: Diffusion, grafting techniques, automation. Scientia Hort. 127:93-105.

Lim, J., T. Kwon, K. Jang, K. Park, J. Hwang, M. Lee, and H. Kim. 2006. Cultivation of hot pepper. Youngyang Pepper Experiment Station, Youngyang, Korea.

Louws, F.J., C.L. Rivard, and C. Kubota. 2010. Grafting fruiting vegetables to manage soil-borne pathogens, foliar pathogens, arthropods and weeds. Scientia Hort. 127:127-146.

Miguel, A., J.V. Maroto, A. San Bautista, C. Baixauli, V. Cebolla, B. Pascual, S. López, and J.L. Guardiola. 2004. The grafting 
of triploid watermelon is an advantageous alternative to soil fumigation by methyl bromide for control of Fusarium wilt. Scientia Hort. 103:9-17.

National Academy of Agricultural Science (NAAS). 2006. Fertilizer recommendation for crops. NAAS, Suwon, Korea. p. 57-58.

Pagamas, P. and E. Nawata. 2008. Sensitive stages of fruit and seed development of chili pepper (Capsicum annuum L. var. Shishito) exposed to high-temperature stress. Scientia Hort. 117:21-25.

Rural Development Administration (RDA). 2008a. Pepper cultivation (The textbook for farming no. 115). RDA, Suwon, Korea.

Rural Development Administration (RDA). 2008b. Vegetable transplant production (The textbook for farming no. 86). RDA, Suwon, Korea.

Rouphael, Y., D. Schwarz, A. Krumbein, and G. Colla. 2010. Impact of grafting on product quality of fruit vegetables. Scientia Hort. 127:172-179.

Sakata, Y., H. Horie, T. Ohara, Y. Kawasaki, and M. Sugiyama. 2008. Influence of rootstock cultivar and storage on the texture of cucumber fruits. J. Japan. Soc. Hort. Sci. 77:47-53.

Schwarz, D., Y. Rouphael, C. Colla, and J.H. Venema. 2010. Grafting as a tool to improve tolerance of vegetables to abiotic stresses: Thermal stress, water stress and organic pollutants. Scientia Hort. 127:162-171.

Traka-Mavrona, E., M. Koutsika-Sotiriou, and T. Pritsa. 2000. Response of squash (Cucurbita spp.) as rootstock for melon (Cucurbita melo L.). Scientia Hort. 83:353-362.

Tsaballa, A., C. Athanasiadis, K. Pasentsis, I. Ganopoulos, I. Nianiou-Obeidat, and A. Tsaftaris. 2013. Molecular studies of inheritable grafting induced changes in pepper (Capsicum annuum) fruit shape. Scientia Hort. 149:2-8.

Yetisir, H., N. Sari, and S. Yücel. 2003. Rootstock resistance to Fusarium wilt and effect on watermelon fruit yield and quality. Phytoparasitica 31:163-169.

Zhao, X., Y. Guo, D.J. Huber, and J. Lee. 2011. Grafting effects on postharvest ripening and quality of 1-methylcyclopropenetreated muskmelon fruit. Scientia Hort. 130:581-587. 